\title{
Maternal health in the Third World
}

\section{Training in community obstetrics is needed}

Effective maternal health care is not reaching the women of the Third World. The maternal mortality is estimated as being over 600 per 100000 live births in Africa and over 400 in Asia. In contrast, the rate for northern Europe is less than 10 per $100000 .^{\prime}$ Study of the causes of these poor results has led to recommendations that there be a change in policy from hospital based services towards community based maternity care. The Safe Motherhood International conference held in Nairobi in 1987 has provided the most authoritative call for action in this respect. ${ }^{2}$ A recent issue of Population Reports reviews the many publications that lead to the same conclusion. ${ }^{3}$

These ideas are not new. In 1979 the seventh study group of the Royal College of Obstetricians made similar recommendations including a call for the training of doctors in maternal and child health. ${ }^{+}$In the same year a working group of the International Federation of Gynaecologists and Obstetricians and the World Health Organisation concluded that obstetricians have a vital role in training and supervising the primary health care team. ${ }^{5}$ Disappointingly, the reports on these meetings led to little response, and five years later Fairweather again had to stress the need for obstetricians to become more involved in community and family health. ${ }^{6}$ Since then, in writing about the neglected tragedy of maternal mortality, Rosenfield and Maine reproached the world's obstetricians for their failure in this respect and for their tendency to concentrate on high technology subspecialities. ${ }^{7}$ The situation is probably little changed. Currently only a few obstetricians seem to play much part in the running of maternal health programmes, and their sphere of activity is mostly within the secondary or tertiary level of the service.

It is time that we asked why this is so. One reason must be that obstetricians are given little training in what can be called either maternal health or community obstetrics. Those obtaining their undergraduate training in a developing country can be expected to receive training in maternal and child health during their course, but it is doubtful if they receive much during their postgraduate training. This is certainly the case for any period that they spend in industrialised countries, where the emphasis is on the development of clinical knowledge and skill. This lack of appropriate training is likely to result in obstetricians either failing to recognise their responsibilities towards the community maternity services or being ill prepared to carry them out.
It is instructive to look at the community related activities that are currently being advocated. The report of the safe motherhoood conference calls for additional studies to gain better information specific to the local on maternal mortality and for continuous operational research and evaluation activities. These clearly need obstetric input, but how can an obstetrician carry out such studies effectively without extra knowledge of epidemiology and medical statistics, some training in health manpower and economics, and knowledge of research methods? The maternity services are said to require development at three levels, those of trained traditional birth attendants, community health centres, and referral centres. It is recommended that appropriate technologies be developed for all levels, and that ancillary health workers be trained to provide antenatal and intrapartum care. But how can obstetricians develop technologies appropriate for the various levels of the service unless they have worked there themselves or had training in the subject? They are also likely to be ineffective teachers of ancillary health workers unless they have had training in developing courses, producing teaching aids, and other aspects of teaching. These examples show the need for a training course in which trainee obstetricians can study these and other community related aspects of their work. This could also be an opportunity for them to reappraise the teaching and experience gained in Western countries, which may be inapplicable in their own countries. $^{8}$

Unfortunately, the low level of medical staffing and shortage of postgraduate institutions in most developing countries are likely to preclude establishing a course locally. The United Kingdom has two schbols of tropical medicine capable of providing support for the community health component of such a course and two departments of tropical or international child health, both of which include maternal health in their curricula, from which expertise could be gained. What is needed, however, is a separate department dedicated to the teaching of community obstetrics or international maternal health. In addition to its teaching role such a department could facilitate the practice of community obstetrics in other ways. It could act as a resource centre, encourage good practice by producing and distributing appropriate case records, participate in developing appropriate technologies, and develop teaching materials. This is something that the Royal College of Obstetricians and 
Gynaecologists could promote as a contribution toward the international efforts being made to raise the standard of maternal health in developing countries.

$\mathrm{C} \mathrm{H}$ W BULLOUGH

Consultant Obstetrician,

South Shields General Hospital,

South Shields NE34 0PL

1 World Health Organisation Division of Family Health. Muternal mortality rates: a tabulation of uruilable information. 2nd ed. Geneva: WHO, 1986

2 Mahler H. The safe motherhood initiative: a call to action. Lancet 1987;ii:668-70.

3 Population Information Program. Mothers' lives matter: maternal health in the community. Popul Rep [L.] 1988:7:12-22.

+ Philpott RH, ed. Matermity servtces in the developing world-what the community needs. London: Ruval College of Obstetricians and Gynaecologists, 1979

5 Caldevro-Barcia R, Dunn PM, eds. Report of the FIGO/WHO workshop on innovitive approaches to maternal and perinatal care as part of primary health care. Geneva: International Federation of Ginecology and Obstetrics, 1979.

6 Fairweather DVI. Problems of health manpower development in obstetrics. Int $\mathcal{f}$ Gynaecol Obstet $1984: 22: 467-70$.

Rosenfield A, Maine D. Maternal mortality-a neglected tragedy: where is the M in MCH. Lancet $1985 ; 1 i: 83-5$

Pinotti JA, Fáundes A. Obstetric and grnaecological care for third world women. Int $f$ Ginnaecol Obstet 1984:22:4+9-55.

\section{Managing acute limb ischaemia}

\section{Demands specialist care when caused by thrombosis}

Acute ischaemia of a limb classically presents with the six p's - pain, pallor, pulselessness, paraesthesia, paralysis, and perishing cold. Most commonly it is caused by an embolus, but another important cause is thrombosis in arteries already affected by occlusive disease. In the case of thrombosis the presentation may be delayed for a few days because the collateral vessels are well developed and carry some blood to the limb. Distinguishing between the two causes of acute ischaemia is important ${ }^{2}$ ' because an embolus is readily treated by embolectomy, ${ }^{3}$ whereas the poorer outcome of thrombosis may be improved by specialist management. ${ }^{+}$

Immediate measures are needed when the foot is white, senseless, and totally ischaemic. Analgesia should be followed by a bolus of heparin to prevent the clot propagating. Emergency embolectomy will usually resolve the problem, but if the result is unsatisfactory an arteriogram should be done while the patient is still on the operating table. This procedure may need to be followed by more distal exploration, arterial reconstruction, or thrombolytic treatment. ${ }^{56}$ The surgeon should not just accept that the embolectomy has failed: the failure probably means that thrombosis rather than embolism is the cause.

If thrombosis is suspected at the outset then an arteriogram must be done. Sometimes this will point toward surgical management, but more often there will be extensive occlusion of vessels and thrombolytic treatment is now a recognised method of management provided that the foot is viable. ${ }^{7-9}$ The cannula that is used to produce the arteriogram is advanced into the thrombus and a low dose of streptokinase (about 5000 units an hour) passed through the cannula. The low dose minimises the chance of systemic effects, but haematological monitoring is essential. Once the thrombus has been lysed, further arteriography will show underlying stenoses and occlusions. These may be treated with angioplasty or bypass grafting. ${ }^{90}$ This modern management demands close cooperation among vascular surgeons, radiologists, and haematologists, which may not be possible in some hospitals.

Once the acute problem is over then a search should be made for the source of any embolus; atrial fibrillation, for instance, suggests that thrombus from the left atrium is the source. Investigations such as echocardiography only rarely help to identify the cause in other patients. "The source of the embolus often remains obscure. There are surprisingly few data on the long term effectiveness of treating patients who have had emboli with anticoagulants or antithrombotic agents. Sparse retrospective reviews suggest that recurrent embolism is common and that anticoagulation reduces its incidence. ${ }^{12-1+}$ In a recent study of 1007 patients with atrial fibrillation randomised to receive warfarin, aspirin, or a placebo only one patient (given aspirin) developed a peripheral embolus, but the incidence of cerebral events was significantly reduced in patients having warfarin. ${ }^{15}$

The main risk of treatment with warfarin is haemorrhage, and an increase in the prothrombin ratio to $1 \cdot 52-2 \cdot 0$ has been recommended to produce adequate anticoagulation without an excessive risk of bleeding. ${ }^{16}$ In one study 93 patients with prothrombin ratios in this range were carefully monitored and followed up for as long as seven years (G R Seabrook and others, American Venous Forum, New Orleans, 1989); the results showed that one patient in 26 might be expected to have a major bleed each year. In practice the risks may be higher because many patients do not comply well with treatment. We need more information on both the risks and the benefits of long term use of anticoagulant drugs or antithrombotic agents in patients with acute ischaemia of a limb.

A good case can be made for vascular surgeons managing all patients with peripheral arterial disease, including those who present as emergencies. ${ }^{17}$ Most hospitals do not, however, have enough staff for this to be realistic, and for the foreseeable future general surgeons will continue to treat these patients. But patients whose acute limb ischaemia is not caused by emboli should be referred to a team of surgeons and radiologists with a special interest in vascular problems.

W BRUCE CAMPBELL

Consultant in Vascular and General Surgery

TIMOTHY R MAGEE

Registrar in Surgery

Royal Devon and Exeter Hospital,

Exeter EX2 5DW

Dale WA Differential management of acute peripheral arterial ischaemia 7 Vosc Surg 1984 1 : 269-78.

2 Jamieson CW. Is it important to differentiate between acute and acute on chronic ischaemia? In Greenhalgh RM. Jamicson CW'. Nicolaides AN, eds. Limb saliage and amputation for z'ascular disease. London: Saunders, 1988: 105-12.

3 Fogarty TJ, Cranley JJ, Krause RJ, Strasser ES, Hafner CD. A method for extraction of arterial emboli and thrombi. Surg Gynecol Obstet 1963;116:241-4

4 Cambria RP, Abbot WM. Acute arterial thrombosis of the lower extremity: its natural history contrasted with arterial embolism. Arch Surg 1984;119:784-7.

5 Quinones-Baldrich WJ, Zierler RE, Hiatt JC. Intra-operative fibrinolytic therapy: an adjunct to catheter thrombo-embolectomy. 7 V'as Surg 1985;2:319-26.

6 Parent FN, Bernhard VM, Pabst TS, McIntyre KE, Hunter (GC, Malone JM. Fibrinolytic treatment of residual thrombus after catheter embolectomy for severe lower limb ischacmia. J'ase Sur 1989:9:153-60.

Katzen BT, Edwards KC, Albert AS, van Breda A. Low dose direct fibrinolysis in peripheral vascular discase. F l'asc Surg 1984;1:718-22.

8 Earnshaw JJ, Gregson RHS, Makin GS, Hopkinson BR. Early results of low dose intra-arterial streptokinase theraps in acute and subacute lower limb arterial ischaemia. Br f S Surg 1987;74: $504-7$

9 Walker WJ, Giddings AEB. A protocol for the safe treatment of acute lower limb ischaemia with intra-arterial streptokinase and surgery. Br 7 Surg 1988;75:1189-92.

$10 \mathrm{Nachbur} \mathrm{BH}$, Schneider $\mathrm{E}$, Largiader J. Is there a case for initial lysis and catheter clot removal for acute ischaemia? In: Greenhalgh RM, Jamieson CW, Nicolaides AN, eds. Limb salvage and amputation for z'ascular disease. London: Saunders, 1988:121-35.

11 Fanning WJ, Vaccaro PS, Satiani B, Smead WL, Das BM. The role of echocardiography in patients with acute peripheral arterial embelization. Annals of Vascular Surgery 1986;1:316-20.

12 Darling RC, Austen W( , Linton RR. Arterial embolism. Surg Gynecol Obstet 1967;124:106-14.

13 (ireen RM, Deweese JA, Rob CG. Arterial embolectomy before and after the Fogarty catheter. Surgers 1975:77:24-33.

14 Hammarsten J. Holm J, Schersten T. Positive and negative effects of anticoagulant treatmen during and after arterial embolectomy. Y Cardiovasc Surg (Torino) 1978;19:373-9.

15 Petersen P. Borsen G, Godtfredsen J, Andersen E, Andersen B. Placebo-controlled, randomised trial of warfarin and aspirin for prevention of thromboembolic complications in chronic atrial fibrillation. The Copenhagen AFASAK studv. Lancet 1989;i:175-9.

16 Petersen EP. Kwaan HC. Current concepts of warfarin therapy. Arch Intern Med 1986;146:581-4.

17 Nachbur BH. Treatment of acute ischaemia: every general surgeon's business? European fournal of V'ascular Surgery 1988:2:281-2. 